\title{
Predictive value of perioperative gastric acid tests
}

\author{
J. M. HOOD, E. F. ANNE SPENCER, K. D. MACRAE, AND T. KENNEDY \\ From the Royal Victoria Hospital, Belfast, Northern Ireland
}

SUMMARY Preoperative acid studies and early postoperative insulin tests in 275 patients undergoing various forms of vagotomy have been related to recurrent ulceration. Follow-up time has been from two to nine years, mean 4.3 years. Recurrence is directly related to basal acidity in both tests but is not related to stimulated acid levels preoperatively. In the insulin tests higher levels of acidity after insulin are associated with a higher incidence of recurrence. When positive, Hollander's and multiple criteria are both associated with a higher recurrence rate.

Gastric function tests involving nasogastric intubation are uncomfortable for the patient, expensive in terms of nursing and technical staff, and may, in the case of insulin tests, carry some risk. Preoperative tests with pentagastrin or other stimulation have been justified as a means of detecting gastrinomas, but these rare tumours can be much more accurately diagnosed by radioimmunoassay of gastrin, a facility which is now widely available.

A policy of tailoring the operation to the preoperative acid output is attractive and has long been advocated. Baron (1973), however, has stated that acid studies are of little value in selecting the operative procedure. Kronborg (1972) found that the incidence of recurrent ulceration after truncal vagotomy and drainage was directly related to the preoperative stimulated acid output.

Insulin tests in the early postoperative period have been widely used to assess the completeness of gastric denervation, but Dragstedt himself (1973) ultimately abandoned the test and relied simply on estimation of basal acid secretion. Kronborg (1971) found the insulin test, as interpreted by the Hollander (1948) criteria, to have no value in predicting ulcer recurrence.

We have made a further attempt to evaluate prooperative pentagastrin tests and early postoperative insulin tests as indicators of the likelihood of ultimate ulcer recurrence.

\section{Methods}

Two-hundred-and-seventy-five prospectively studied patients were followed up for two to nine years, a mean of 4.3 years. Each of these patients had been

Received for publication 9 July 1976 randomly allocated to one of five different operations, without regard to preoperative acid levels. The operations were: selective vagotomy and pyloroplasty (101); selective vagotomy and gastrojejunostomy (79); truncal vagotomy and pyloroplasty (50); proximal gastric vagotomy without drainage (32); and proximal gastric vagotomy with gastrojejunostomy (13).

Maximal acid output in the five groups did not differ significantly nor did basal acid in the first four groups; basal acid was significantly lower in the 13 patients who had PGV and GJ, a small group in which there were no recurrences. There were 16 recurrent ulcers in all but the rate of recurrence did not differ significantly in the five groups; there is therefore no evidence that any one operation was worse than the others in this respect.

In the preoperative tests the position of the tube in the body of the stomach was first established by screening. The basal acid output (BAO) was then measured during the resting hour, after careful aspiration of residual juice. Pentagastrin $(0.006 \mathrm{mg} / \mathrm{kg})$ was injected intramuscularly and the acid output in the subsequent hour (MAO) was measured in four 15-minute specimens; the sum of the highest two consecutive specimens multiplied by two was recorded as the PAO.

Insulin tests were carried out about the 10th postoperative day, aspirating through a double lumen gastrostomy tube (Burns and Menzies, 1966) placed in the stomach at operation and sutured with the gastric limb lying at the junction of the antrum and the body. The BAO was measured as above. In addition the maximum output in any one of the first two hours after the intravenous injection of insulin $(0.2 \mu / \mathrm{kg})$ was recorded (MIAO) and the total output in the two post-insulin hours (TIAO). The 
peak acid output (PIAO) was the sum of the two highest consecutive 10-minute periods, multiplied by three. Hollander's criteria were applied and results were also assessed using the multiple criteria of Bank et al. (1967).

\section{Results}

Although 275 patients were studied, not every one had both tests and in some, for technical reasons, the tests were invalid. As a result only 253 patients had a pentagastrin test and 257 an acceptable insulin test.

The mean levels of BAO, MAO, and PAO in preoperative pentagastrin tests are given in Table 1. There was no difference in the MAO or PAO of those who developed recurrent ulcer compared with those who did not. The BAO, however, differed significantly (Figure). Patients who developed recurrence had a mean BAO of $8.7 \mathrm{mmol}$, double the level in those who remained free. The rate of recurrence increased step-wise with increasing levels of basal acid from $1.4 \%$ with BAO less than $2 \mathrm{mmol}$ to $18.5 \%$ when the BAO was above $10 \mathrm{mmol}$ (Table 2).

Early postoperative insulin test results showed significantly higher acid levels in those patients who developed recurrent ulceration, the BAO showing the least difference (Table 3). With the application of strict Hollander criteria, there were 24 positive tests

Table 1 Preoperative pentagastrin test

\begin{tabular}{llll}
\hline $\begin{array}{l}\text { Mmol } \\
(\text { mean })\end{array}$ & $\begin{array}{l}\text { Recurrence }-v e \\
(n=237)\end{array}$ & $\begin{array}{l}\text { Recurrence }+v e \\
(n=16)\end{array}$ \\
\hline BAO & 4.35 & 8.72 & P $<0.001$ \\
PAO & 41.79 & 40.71 & NS \\
MAO & 30.37 & 30.89 & NS \\
\hline
\end{tabular}

Table 2 Influence of preoperative acid on recurrence

\begin{tabular}{llll}
\hline $\begin{array}{l}\text { BAO } \\
(\text { mmol/h) }\end{array}$ & Patients & Recurrences & $\begin{array}{l}\text { Recurrence rate } \\
\%\end{array}$ \\
\hline$<2$ & 73 & 1 & $1 \cdot 4$ \\
$2-5$ & 90 & 4 & $4 \cdot 4$ \\
$5-10$ & 63 & 6 & $9 \cdot 5$ \\
$>10$ & 27 & 5 & $18 \cdot 5$ \\
\hline
\end{tabular}

$<2$ mmol compared with $>10 \mathrm{mmol} P<0.01$.

2 to $5 \mathrm{mmol}$ compared with $>10 \mathrm{mmol} \mathrm{P}<0.05$.

Table 3 Early postoperative insulin test (in 257 patients)

\begin{tabular}{llll}
\hline $\begin{array}{l}\text { Mmol } \\
\text { (mean) }\end{array}$ & $\begin{array}{l}\text { Recurrence }-v e \\
(n=24)\end{array}$ & $\begin{array}{l}\text { Recurrence }+v e \\
(n=10)\end{array}$ \\
\hline BAO & 0.82 & 1.77 & $\mathrm{P}<0.05$ \\
PIAO & 1.26 & 4.96 & $\mathrm{P}<0.001$ \\
MIAO & 0.87 & 3.20 & $\mathrm{P}<0.001$ \\
TIAO & 1.13 & 4.32 & $\mathrm{P}<0.001$ \\
\hline
\end{tabular}

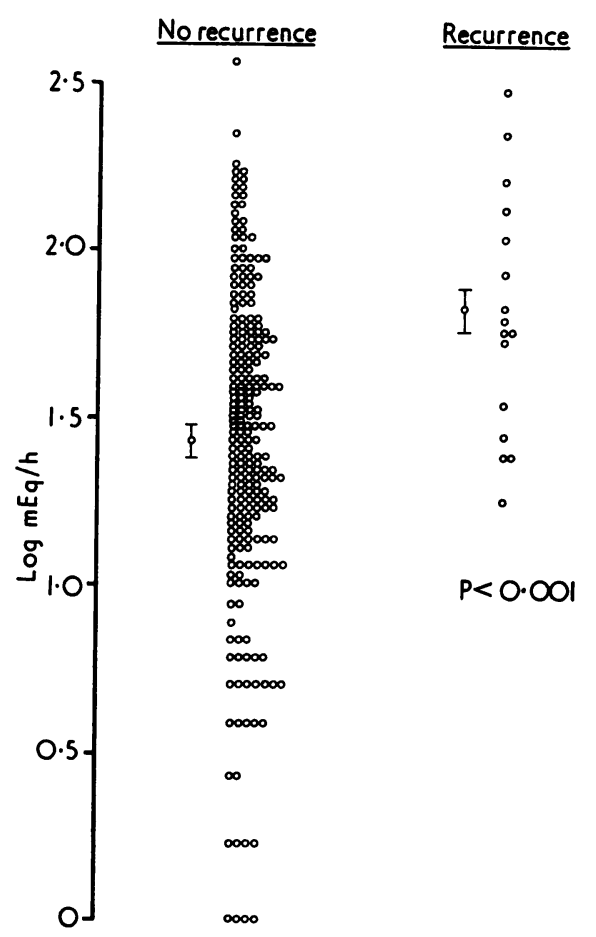

Figure Preoperative basal acid output in 253 patients. $\Phi= \pm I S E M$. The log transformation was carried out on the data coded without the decimal point so the transformation is $y=\log n(10 \chi)$

and $20.8 \%$ of these patients ultimately developed recurrence compared with $3.9 \%$ of the 233 patients with negative criteria $(P<0.01)$.

When three, four, or five of the multiple criteria were positive the recurrence rate was $18.3 \%$ compared with a rate of $4.3 \%$ when two, one, or none were positive $(P<0.05)$. When all five criteria were negative the recurrence rate was $3 \%(P<0.01) \cdot \chi^{2}$ test was used throughout.

\section{Discussion}

The suggestion that the choice of operation for duodenal ulcer should be based on the results of preoperative acid stimulation tests (Small et al., 1967) depends on the assumption that there is an increased risk of recurrent ulcer with increasing levels of stimulated acid secretion (Kronborg, 1972). Our study does not show this association but does show a correlation between BAO and recurrence.

It is conceded that BAO results are not always reproducible (Baron, 1973) nor did we make allowances for pyloric loss or duodenal reflux (Faber et al., 1974). Nevertheless, our results showed a strong 
association between preoperative BAO and the risk of recurrence; a similar association with high postoperative BAO was also found. This probably indicates incomplete vagotomy; it is, after all, one of the multiple criteria (Bachrach, 1962). In individual patients there was no correlation between preand postoperative BAO. High BAO may indicate antral G-cell overactivity or hyperplasia, a credible cause of recurrent ulceration. Although the percentage of recurrent ulcers increases significantly as the level of preoperative basal acid increases, the number of recurrences in this series is not sufficient to allow a precise statistical estimate to be made of the recurrence risk for any individual patient; all that can be said is that there is a trend to the disadvantage of those with a high basal acid.

Insulin tests were performed about 10 days after operation and in our series have been of some predictive value. The incidence of recurrence in those with positive Hollander criteria was significantly increased. Similarly, when three or more of the multiple criteria of Bank, Marks, and Louw were positive there was a greater chance of recurrence. We cannot explain why about four-fifths of our patients, who were positive in each case, did not develop recurrence; perhaps a longer follow-up will alter this proportion. A recurrence rate of about $4 \%$ in those with entirely negative tests may indicate that at this early stage the test is not a good index of the completeness of vagotomy. Early insulin tests have been criticised on the grounds that reversion of negative to positive frequently occurs (Ruckley et al., 1970; Smith et al., 1972). Though accepting that later insulin tests may be preferable, we have found difficulty in persuading symptomless patients to leave work for even half a day to have such tests performed and the number of late tests in our practice has been small. The volume of gastric juice, corrected for pyloric reflux, after insulin stimulation has also been shown to be of predictive value (Faber et al., 1975). We have no figures to support this finding.

Consideration of our data leads us to suggest that preoperatively a measurement of basal acid output is all that is required. If the BAO is high-say $5 \mathrm{mEq}$ per hour or more-the test should be repeated and gastrin estimation should be performed. In this way, patients with gastrinomas and those with antral G-cell hyperplasia should be identified (Ganguli et al., 1974) the latter being treated by vagotomy and antrectomy.

Postoperatively, the insulin test is perhaps of value to monitor the performance of the surgeon (Johnston and Goligher, 1971) but almost as much help in predicting the risk of recurrence in the individual patient can be had from a simple measurement of basal output.

\section{References}

Bachrach, W. H. (1962). Laboratory criteria for the completeness of vagotomy. American Journal of Digestive Diseases, 7, 1071-1085.

Bank, S., Marks, I. N., and Louw, J. H. (1967). Histamineand insulin-stimulated gastric acid secretion after selective and truncal vagotomy. Gut, 8, 36-41.

Baron, J. H. (1973). Clinical application of gastric secretion measurements. Clinics in Gastroenterology, 2, 293-314.

Burns, G. P., and Menzies, T. (1966). A new double-lumen gastrostomy tube for use after vagotomy. British Journal of Surgery, 53, 433.

Dragstedt, L. R. (1973). Vagotomy on Trial. Edited by A. G. Cox and J. Alexander Williams. Heinemann: London.

Faber, R. G., Russell, R. C. G., Royston, C. M. S., Whitfield, P., and Hobsley, M. (1974). Duodenal reflux during insulin-stimulated secretion. Gut, 15, 880-884.

Faber, R. G., Russell, R. C. G., Parkin, J. V., Whitfield, P., and Hobsley, M. (1975). The predictive accuracy of the post-vagotomy insulin test: a new interpretation. Gut, 16, 337-342.

Ganguli, P. C., Pearse, A. G. E., Polak, J. M., Elder, J. B., and Hegarty, M. (1974). Antral-gastrin-cell hyperplasia in peptic-ulcer disease. Lancet, 1, 583-586.

Hollander, F. (1948). Laboratory procedures in the study of vagotomy (with particular reference to the insulin test). Gastroenterology, 11, 419-425.

Johnston, D., and Goligher, J. C. (1971). The influence of the individual surgeon and of the type of vagotomy upon the insulin test after vagotomy. Gut, 12, 963-967.

Kronborg, O. (1971). The value of the insulin test in predicting recurrence after vagotomy and drainage for duodenal ulcer. Scandinavian Journal of Gastroenterology, 6, 471-478.

Kronborg, O. (1972). Influence of the number of parietal cells on risk of recurrence after truncal vagotomy and drainage for duodenal ulcer. Scandinavian Journal of Gastroenterology, 7, 423-431.

Ruckley, C. V., Sircus, W., Falconer, C. W. A., Small, W. P., and Smith, A. N. (1970). Recurrent ulcer and postvagotomy gastric acid secretion (Abstract). Gut, 11, 1061.

Small, W. P., Bruce, J., Falconer, C. W. A., Sircus, W., and Smith, A. N. (1967). The results of a policy of selective surgical treatment of duodenal ulcer. British Journal of Surgery, 54, 838-841.

Smith, I. S., Gillespie, G. B., Elder, J. B., Gillespie, I. E., and Kay, A. W. (1972). Time of conversion of insulin response after vagotomy. Gastroenterology, 62, 912-917. 